\title{
Prognostic clinicopathologic factors in carcinoma of unknown primary origin: a study of 106 consecutive cases
}

\author{
Junjeong Choi ${ }^{1, *}$, Ji Hae Nahm ${ }^{2, *}$ and Sang Kyum Kim² \\ ${ }^{1}$ College of Pharmacy, Yonsei Institute of Pharmaceutical Sciences, Yonsei University, Incheon, Republic of Korea \\ 2 Department of Pathology, Yonsei University College of Medicine, Seoul, Republic of Korea \\ * These authors have contributed equally to this work \\ Correspondence to: Sang Kyum Kim, email: nicekyumi@yuhs.ac \\ Keywords: carcinoma of unknown primary origin, CK20, Culine's prognostic model, prognosis, unfavorable group \\ Received: July 22, 2016 \\ Accepted: February 20, 2017 \\ Published: March 08, 2017
}

Copyright: Choi et al. This is an open-access article distributed under the terms of the Creative Commons Attribution License 3.0 (CC BY

3.0), which permits unrestricted use, distribution, and reproduction in any medium, provided the original author and source are credited.

\section{ABSTRACT}

A heterogeneous group of cancers for which the site of origin remains occult after detailed investigations is defined as carcinomas of unknown primary origin (CUPs). Because patients with CUP have a dismal prognosis, we have analyzed CUPs to highlight the implication of clinicopathologic factors related with patient survival. A total of 106 consecutive cases of CUP were collected. A two-step strategy of immunohistochemistry to assess CUPs according NCCN Guidelines is used to separate carcinomatous tumors and subtype carcinomas. Median follow up of censored patients was 26 months. Median survival time of whole patients was 13 months (95\% confidence interval $[\mathrm{CI}], 8.43-19.1$ months), with one, two and fiveyear survival rate of $53.7 \%, 35.1 \%$, and $30.5 \%$, respectively. Factors related with shorter overall survival was adenocarcinoma histology $(P=0.001)$, increased CA19$9(P=0.003)$, increased CEA $(P=0.047)$, increased LDH $(P<0.001)$, CK20 positivity $(P=0.002)$, presence of bone metastasis $(P=0.017)$, metastasis not confined to the lymph nodes $(P=0.015)$, unfavorable clinical group based predefined category $(P=0.017)$, and patients with no treatment $(P<0.001)$. Multivariable analysis with cox regression model revealed factors related with overall survival; cases belonged to Culine's poor risk group (HR, 3.88; 95\% CI, 1.75-8.64; $P=0.001)$ and CK20 positivity ( $H R, 3.31 ; 95 \% C I, 1.42-7.70 ; P=0.005)$. In conclusion, the CK20 expression profile is a prognostic factor in patients with CUP and initial stratification of patient with Culine's model may provide a prognostic information in these patients. Assessment of clinical implication of these factors in the context of site specific therapy needs to be evaluated.

\section{INTRODUCTION}

Carcinoma of unknown primary origin (CUP), also known as occult primary tumor is defined as histologically proven metastatic malignant tumors whose primary site cannot be identified by clinical manifestation, radiographic and pathologic examinations $[1,2]$. It comprises heterogeneous groups of tumor, clinically and histologically and about $3 \%$ to $5 \%$ of all newly diagnosed malignant tumors are classified as CUP [2].

Among CUPs, adenocarcinoma comprises the most common histologic type in reported studies [3, 4].
Generally, patients of CUP have poor clinical prognosis with limited life expectancy. Median survival of 3 months in extranodal adenocarcinoma and 8 months in metastatic adenocarcinoma limited to lymph node are expected in population based analysis [4]. In addition, it is rapidly invasive with early dissemination, and shows unpredictable pattern of metastatic spread.

Although the primary site of a CUP remains unknown in $20-50 \%$ of patient even after a full diagnostic workup [5], it is known that a subset of patients with CUP shows favorable clinical behavior. Identification of this group seems pivotal in the management of patients. Favorable subsets of patients accounts for about $20 \%$ 
of those with CUPs, and include women with papillary adenocarcinoma of the peritoneal cavity, women with adenocarcinoma involving the axillary lymph nodes, poorly differentiated carcinoma with midline distribution, poorly differentiated neuroendocrine carcinoma, squamous cell carcinoma involving cervical lymph nodes, adenocarcinoma with a colon-cancer profile, men with osteoblastic bone metastases and elevated prostatespecific antigen, isolated inguinal lymphadenopathy with squamous histology, and patients with one, small, or potentially resectable tumor [6].

The best approach of stepwise algorithm with immunohistochemistry (IHC) of biopsied tissue was suggested to provide a specific therapy against the most likely primary site. Although a number of recent studies discussed the use of gene expression-based tests and methylation profile in the setting of CUP, practical value of this approach in the daily clinical practice is still limited [7-10]. Thus, a cost-effective and systemized IHC with identification of clinicopathologic factors related with the patient prognosis are clinically relevant $[11,12]$. Most of previous reported publication focused on the usage of appropriate IHC panel for the differential diagnosis. Limited number of publication described general clinical behavior and clinicopathologic factors related with them $[13,14]$. In the present study, consecutive cases of CUPs from one institute were analyzed to highlight the implication of clinicopatholoic factors related with patient survival.

\section{RESULTS}

\section{Patient demographic characteristics and clinical manifestation}

A total of 106 cases from 106 patients were collected from the year of 2000 to 2015 . Clinicopathologic characteristics of the patients are presented in Table 1. Median age at time of diagnosis is 59 (range: 25-83) and the number of male patients are sixty nine (65.1\%). Most common histologic type was adenocarcinoma (43 cases, $40.6 \%$ ), followed by squamous cell carcinoma (28 cases, $26.4 \%$ ), poorly differentiated carcinoma (26 cases, 24.5\%) and undifferentiated carcinoma (9 cases, $8.5 \%$ ). Representative images of $\mathrm{H}-\mathrm{E}$ stained section are displayed in Figure 1. Cases of poorly differentiated carcinoma showing neuroendocrine differentiation, confirmed by the IHC, were reported in 4 cases.

About 72.6\% (77 out of 106) of patients were treated by chemotherapy and radiation concurrently or sequentially. Metastasis to liver, lung, bone and brain was noted in $10(9.4 \%), 17(16.0 \%), 28(26.4 \%)$

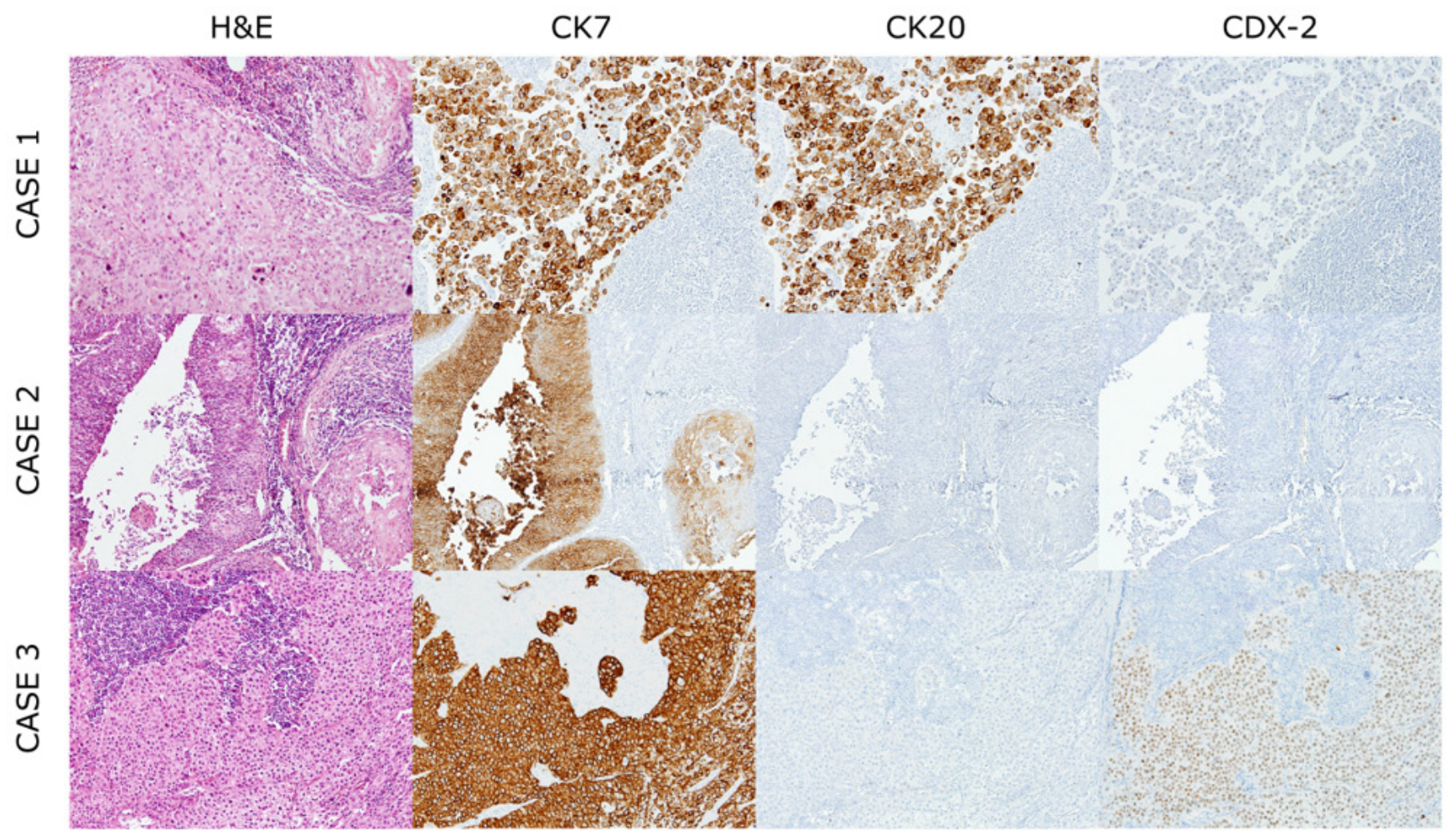

Figure 1: Representative histological features of cancers of unknown primary origin. Case1; Poorly differentiated carcinoma, positive for CK7 and CK20 and focal positive for CDX-2. Case2; Squamous cell carcinoma, positive for CK7. Case3; Undifferentiated carcinoma, positive for CK7 and CDX-2 and negative for CK20. 
Table 1: Clinicopathologic characteristics of patients with CUP

\begin{tabular}{|c|c|c|c|}
\hline Variable & Patients N(\%)(total=106) & Variable & Patients N(\%)(total=106) \\
\hline Age(years) & & Bone Metastasis & \\
\hline Median & $59(25-83)$ & Absent & $78(73.6)$ \\
\hline$<50$ & $28(26.4)$ & Present & $28(26.4)$ \\
\hline \multirow[t]{2}{*}{$>50$} & $78(73.6)$ & Treatment & \\
\hline & & No treatment & $19(17.9)$ \\
\hline Gender & & Operation & $40(37.7)$ \\
\hline Female & $37(34.9)$ & Chemotherapy & $41(38.7)$ \\
\hline Male & $69(65.1)$ & Radiation therapy & $44(41.5)$ \\
\hline Performance Status(ECOG) & & Concurrent chemo-radiation & $16(15.1)$ \\
\hline 0 & $13(12.6)$ & & \\
\hline 1 & $86(81.1)$ & CEA & \\
\hline 2 & $4(3.8)$ & Normal & $48(45.3)$ \\
\hline 3 & $1(0.9)$ & High & $32(30.2)$ \\
\hline 4 & $2(1.9)$ & Not assessed & $26((24.5)$ \\
\hline Histology & & CA19-9 & \\
\hline Poorly differentiated carcinoma & $26(24.5)$ & Normal & $45(42.5)$ \\
\hline Adenocarcinoma & $43(40.6)$ & High & $26(24.5)$ \\
\hline Squamous cell carcinoma & $28(26.4)$ & Not assessed & $35(33.0)$ \\
\hline Undifferentiated carcinoma & $9(8.5)$ & CA125 & \\
\hline Lactate dehydrogenase(IU/L) & & Normal & $16(15.1)$ \\
\hline Normal & $14(13.2)$ & High & $24((22.6)$ \\
\hline High & $36(34.0)$ & Not assessed & 66.(62.3) \\
\hline Not assessed & $56(52.8)$ & CA15-3 & \\
\hline CK7 immunosttinng & & Normal & $20(18.9)$ \\
\hline Negative & $27(25.5)$ & High & $6(5.6)$ \\
\hline Positive & $60(56.6)$ & Not assessed & $80(75.5)$ \\
\hline Not assessed & $19(17.9)$ & AFP & \\
\hline CK20 Immunostaining & & Normal & $48(45.3)$ \\
\hline Negative & $77(72.6)$ & High & $3(2.8)$ \\
\hline Positive & $10(9.4)$ & Not assessed & $55(51.9)$ \\
\hline Not assessed & $19(17.9)$ & PIVKA-II & \\
\hline CDX2 Immunostaining & & Normal & $18(17.0)$ \\
\hline Negative & $76(71.7)$ & Increased & $12(11.3)$ \\
\hline Positive & $11(10.4)$ & Not assessed & $76(71.7)$ \\
\hline Not assessed & $19(17.9)$ & SCCAg & \\
\hline Lung Metastasis & & Normal & $20(18.9)$ \\
\hline Absent & $89(84.0)$ & Increased & $8(7.5)$ \\
\hline Present & $17(16.0)$ & Not assessed & $78(73.6)$ \\
\hline \multicolumn{4}{|l|}{ Liver Metastasis } \\
\hline Absent & $96(90.6)$ & Prognostic group & \\
\hline Present & $10(9.4)$ & Favorable & $31(29.2)$ \\
\hline Brain Metastasis & & Non-favorable & $75(70.8)$ \\
\hline Absent & $70(66.0)$ & Lower GI profile & \\
\hline Present & $8(7.5)$ & Lower GI profile & $6(5.7)$ \\
\hline Symptomatically suspicous & $2(1.9)$ & Non-Lower GI profile & $81(76.4)$ \\
\hline Not evaluated & $26(24.5)$ & Not assessed & 19(17.9) \\
\hline
\end{tabular}


and $10(9.4 \%)$ patients, respectively. Tumor markers at the time of diagnosis were assessed and elevated carcinoembryonic antigen (CEA), cancer antigen (CA) 19-9, CA125, CA15-3, and alpha fetoprotein (AFP) were recorded in $32(30.2 \%), 26(24.5 \%), 24(22.6 \%)$, $6(5.6 \%)$ and $3(2.8 \%)$ patients, respectively. When CUP patients were categorized into the 'favorable' and 'non-favorable' groups based on predefined criteria, the number of cases belonging to the favorable group was $31(29.2 \%)$, compatible with the previously known range of about $80 \%$. Among these 19 patients (17.9\%) presented as squamous cell carcinoma of the cervical lymph nodes, 4 patients presented as poorly differentiated carcinoma with neuroendocrine characteristics proven by immunohistochemistry, 6 patients with adenocarcinoma with colon-cancer profile and 2 male patients with blastic bone metastases and elevated prostate-specific antigen.

\section{Univariate analysis of clinicopathologic factors related to the patient's survival}

The overall survival probability for the entire CUP study patients is displayed in Figure 2. A total of 39 cases were censored and death event were 67 cases. Median follow up of censored patients was 26.7 months. Median survival time was 13 months (95\% confidence interval [CI], 8.43 - 19.1 months), with one, two and five-year survival rate of $53.7 \%, 35.1 \%$, and $30.5 \%$, respectively, which is better than reported (Figure 2).

Given the importance of the identification of subgroups with favorable clinical behavior, several clinicopathologic factors were analyzed to identify factors related with overall survival and are summarized in Table 2, Figure 3 and Supplementary Figure 1. Factors related with shorter overall survival was presence of bone metastasis $(P=0.017)$, metastasis not confined to the lymph nodes $(P=0.002)$, patients with no treatment $(P<$ $0.001)$, adenocarcinoma phenotype $(P<0.001)$, increased CA19-9 $(P=0.003)$, increased CEA $(P=0.047)$, patients belonging to poor risk group in Culine's model $(P<0.001)$ and increased lactate dehydrogenase (LDH, $P<0.001)$. In the female subset, patients with axillary lymph node metastasis showed tendency of better overall survival, although not statistical significant $(P=0.057)$.

We assessed immunohistochemical results of CK20, CK7 and CDX-2 using TMA and analyzed expression profiles related with patients' overall survival. In lower gastrointestinal profiles, patients with CK20 positive CUP had a poorer overall survival than patients with CK20 negative CUP $(P=0.002)$ and CDX-2 expression $(P=$ 0.042). Patients with CK7 positive CUP also tended to have a shorter overall survival than patients with $\mathrm{CK} 7$ negative CUP $(P=0.111)$.

Patients belonging to favorable prognostic group showed better overall survival than unfavorable group with limited statistical significance $(P=0.191)$. In validation of Culine's prognostic model, median survival of good risk patient was 19 months whereas that of poor risk patients were 7 months (hazard ratio [HR], 2.45; 95\% CI, $1.46-4.10 ; P<0.001)$.

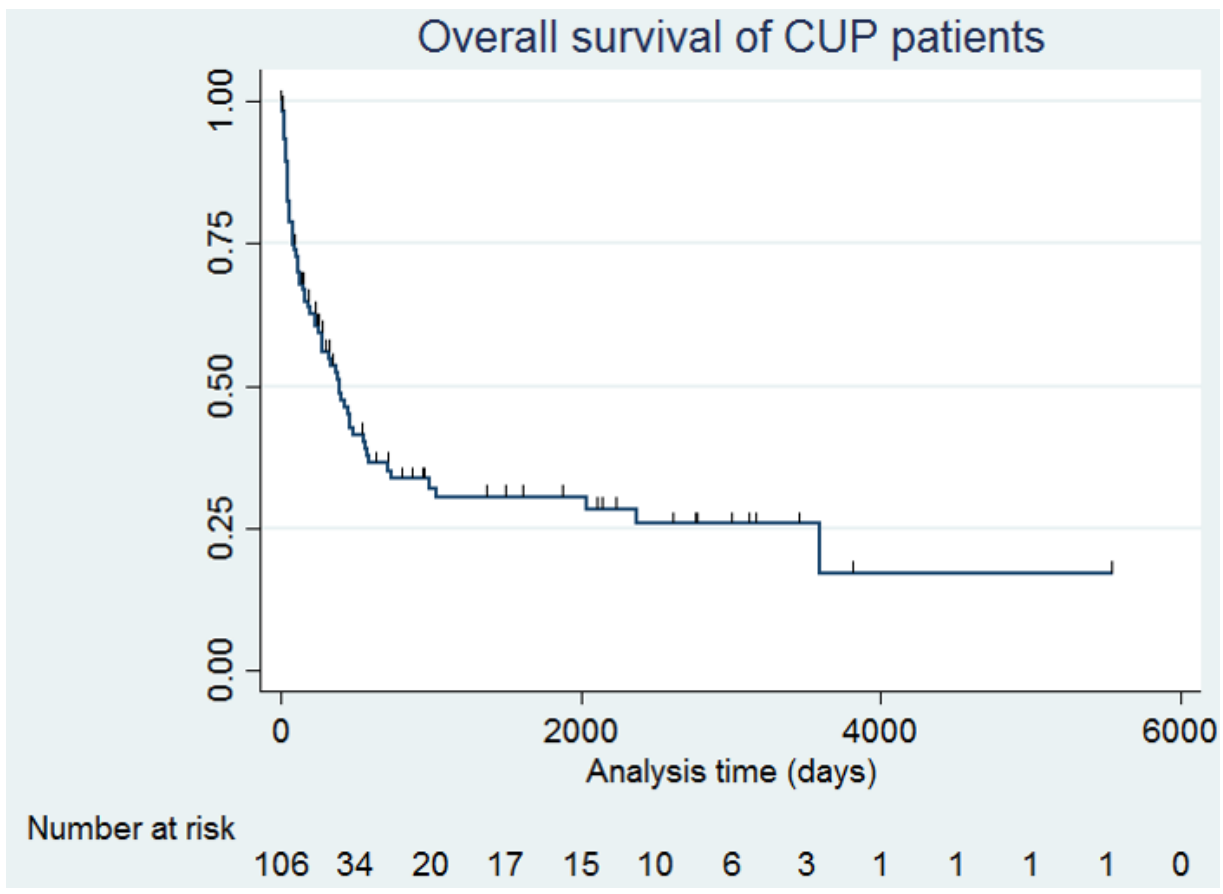

Figure 2: A Kaplan-Meier graph of overall survival of all patients. 
Table 2: Univariate analysis of clinicopathologic characteristic related with overall survival

\begin{tabular}{|c|c|c|c|c|}
\hline Variable & Patients N(\%) & Event & Median survival(months) & $P$ value \\
\hline \multicolumn{5}{|l|}{ Age(years) } \\
\hline$<50$ & $28(26.4)$ & 17 & 19 & \multirow{2}{*}{0.2238} \\
\hline$>50$ & $78(73.6)$ & 50 & 12 & \\
\hline \multicolumn{5}{|l|}{ Gender } \\
\hline Female & $37(34.9)$ & 24 & 12 & \multirow{2}{*}{0.8384} \\
\hline Male & $69(65.1)$ & 43 & 13 & \\
\hline \multicolumn{5}{|l|}{ Performance Status(ECOG) } \\
\hline 0 & $13(12.3)$ & 6 & 78 & \multirow{5}{*}{0.0014} \\
\hline 1 & $86(81.1)$ & 57 & 12 & \\
\hline 2 & $4(3.8)$ & 2 & 2 & \\
\hline 3 & $1(0.9)$ & 0 & 0 & \\
\hline 4 & $2(1.9)$ & 2 & 1 & \\
\hline \multicolumn{5}{|l|}{ Histology } \\
\hline Poorly differentiated carcinoma & $26(24.5)$ & 15 & 18 & \multirow{4}{*}{0.0016} \\
\hline Adenocarcinoma & $43(40.6)$ & 32 & 4 & \\
\hline Squamous cell carcinoma & $28(26.4)$ & 15 & 24 & \\
\hline Undifferentiated carcinoma & $9(8.5)$ & 5 & 119 & \\
\hline \multicolumn{5}{|l|}{ Lactate dehydrogenase(IU/L) } \\
\hline Normal & $14(13.2)$ & 4 & 6 & \multirow{3}{*}{0.0002} \\
\hline High & $36(34.0)$ & 27 & 0 & \\
\hline Not assessed & $56(52.8)$ & & & \\
\hline \multicolumn{5}{|l|}{ CK7 immunosttinng } \\
\hline Negative & $27(25.5)$ & 17 & 24 & \multirow{2}{*}{0.1111} \\
\hline Positive & $60(56.6)$ & 42 & 9 & \\
\hline Not assessed & $19(17.9)$ & & & \\
\hline \multicolumn{5}{|l|}{ CK20 Immunostaining } \\
\hline Negative & $77(72.6)$ & 50 & 14 & \multirow{2}{*}{0.002} \\
\hline Positive & $10(9.4)$ & 9 & 1 & \\
\hline Not assessed & $19(17.9)$ & & & \\
\hline \multicolumn{5}{|l|}{ CDX2 Immunostaining } \\
\hline Negative & $76(71.7)$ & 51 & 14 & \multirow{2}{*}{0.0418} \\
\hline Positive & $11(10.4)$ & 8 & 1 & \\
\hline Not assessed & $19(17.9)$ & & & \\
\hline \multicolumn{5}{|l|}{ Lung Metastasis } \\
\hline Absent & $89(84.0)$ & 55 & 2 & \multirow{2}{*}{0.2142} \\
\hline Present & $17(16.0)$ & 12 & 0 & \\
\hline \multicolumn{5}{|l|}{ Liver Metastasis } \\
\hline Absent & $96(90.6)$ & 60 & 13 & \multirow{2}{*}{0.4388} \\
\hline Present & $10(9.4)$ & 7 & 7 & \\
\hline \multicolumn{5}{|l|}{ Bone Metastasis } \\
\hline Absent & $78(73.6)$ & 47 & 15 & \multirow{2}{*}{0.0171} \\
\hline Present & $28(26.4)$ & 20 & 5 & \\
\hline Brain Metastasis & & & & \\
\hline Absent & $70(66.0)$ & 38 & 16 & 7607 \\
\hline Present & $8(7.5)$ & 8 & 24 & 0.6027 \\
\hline Symptomatically suspicous & $2(1.9)$ & & & \\
\hline Not evaluated & $26(24.5)$ & & & \\
\hline Treatment & & & & \\
\hline
\end{tabular}




\begin{tabular}{|c|c|c|c|c|}
\hline No treatment & 19(17.9) & 10 & 2 & \multirow{5}{*}{0.0000} \\
\hline Operation & $40(37.7)$ & 11 & 6 & \\
\hline Chemotherapy & $41(38.7)$ & 13 & 13 & \\
\hline Radiation therapy & $44(41.5)$ & 15 & 7 & \\
\hline Concurrent chemoradiation & $16(15.1)$ & 18 & 34 & \\
\hline \multicolumn{5}{|l|}{ CEA } \\
\hline Normal & $48(45.3)$ & 30 & 14 & \multirow{2}{*}{0.0468} \\
\hline High & $32(30.2)$ & 23 & 4 & \\
\hline Not assessed & $26(24.5)$ & & 0 & \\
\hline \multicolumn{5}{|l|}{ CA19-9 } \\
\hline Normal & $45(42.5)$ & 25 & 15 & \multirow{2}{*}{0.0031} \\
\hline High & $26(24.5)$ & 21 & 2 & \\
\hline Not assessed & $35(33.0)$ & & 0 & \\
\hline \multicolumn{5}{|l|}{ CA125 } \\
\hline Normal & $16(15.1)$ & 13 & 12 & \multirow{2}{*}{0.7652} \\
\hline High & $24(22.6)$ & 18 & 4 & \\
\hline Not assessed & $66(62.3)$ & & 0 & \\
\hline \multicolumn{5}{|l|}{ CA15-3 } \\
\hline Normal & $20(18.9)$ & 13 & 13 & \multirow{2}{*}{0.5559} \\
\hline High & $6(5.6)$ & 5 & 4 & \\
\hline Not assessed & $80(75.5)$ & & 0 & \\
\hline AFP & & & $\mathbf{0}$ & \\
\hline Normal & $48(45.3)$ & 31 & 14 & \multirow{2}{*}{0.1506} \\
\hline High & $3(2.8)$ & 2 & 0 & \\
\hline Not assessed & $55(51.9)$ & & 0 & \\
\hline \multicolumn{5}{|l|}{ PIVKA-II } \\
\hline Normal & $18(17.0)$ & 14 & 6 & \multirow{2}{*}{0.6332} \\
\hline Increased & $12(11.3)$ & 9 & 3 & \\
\hline Not assessed & $76(71.7)$ & & & \\
\hline \multicolumn{5}{|l|}{ SCCAg } \\
\hline Normal & $20(18.9)$ & 14 & 14 & 0.6109 \\
\hline Increased & $8(7.5)$ & 6 & 9 & \\
\hline Not assessed & $78(73.6)$ & & & \\
\hline Prognostic group & & & $\mathbf{0}$ & \\
\hline Favorable & $31(29.2)$ & 19 & 20 & \multirow{2}{*}{0.191} \\
\hline Non-favorable & $75(70.8)$ & 48 & 11 & \\
\hline \multicolumn{5}{|l|}{ Prognostic group (by Culine) } \\
\hline Good risk & $64(60.4)$ & 36 & 19 & \multirow{2}{*}{0.0005} \\
\hline Poor risk & $42(39.6)$ & 31 & 7 & \\
\hline \multicolumn{5}{|c|}{ Metastasis confined to lymph node } \\
\hline Yes & $36(34.0)$ & 16 & 9 & \multirow{2}{*}{0.0015} \\
\hline No & $70(66.0)$ & 51 & 78 & \\
\hline \multicolumn{5}{|l|}{ Lower GI profile } \\
\hline Lower GI profile & $6(5.7)$ & 5 & 13 & \multirow{2}{*}{0.126} \\
\hline Non-Lower GI profile & $81(76.4)$ & 54 & 1 & \\
\hline Not assessed & 19(17.9) & & & \\
\hline
\end{tabular}

\section{Multivariable analysis of clinicopathologic factors related to the patient's survival}

For adjustment of parameters affecting a patient's survival, multivariable analysis was performed using Cox regression test (Table 3). Multivariable analysis using 
Table 3: Multivariable analysis of clinicopathologic factors related to survival

\begin{tabular}{|c|c|c|c|}
\hline Variable & HR & $95 \% \mathrm{CI}$ & $\mathbf{P}$ \\
\hline \multicolumn{4}{|l|}{ Culine's prognostic model } \\
\hline Poor risk group $v s$. good risk group & 3.88 & $1.75-8.64$ & 0.001 \\
\hline \multicolumn{4}{|l|}{ Histologic subtype } \\
\hline Adenocarcinoma $v s$. other subtypes & 1.51 & $0.76-2.97$ & 0.24 \\
\hline \multicolumn{4}{|l|}{ Lymph node metastasis } \\
\hline Lymph node involement only $v s$. lymph node and distant organ metastasis & 0.86 & $0.34-2.16$ & 0.76 \\
\hline \multicolumn{4}{|l|}{ Bone metastsis } \\
\hline Present vs. absent & 1.43 & $0.67-3.04$ & 0.36 \\
\hline \multicolumn{4}{|l|}{ CA19-9 level } \\
\hline Elevation $v s$. normal range & 1.98 & $0.99-3.97$ & 0.053 \\
\hline \multicolumn{4}{|l|}{ CK20 expression } \\
\hline Positivity $v s$. negativity & 3.31 & $1.42-7.70$ & 0.005 \\
\hline
\end{tabular}

adenocarcinoma histology, CK20 positivity, CA19-9 elevation, metastasis confined to lymph nodes, presence of bone metastasis and favorable group defined by Culine's prognostic model was developed. Finally, factors related with overall survival were cases belonged to Culine's poor risk group (HR, 3.88; 95\% CI, 1.75-8.64; $P=0.001)$ and CK20 positivity (HR, 3.31; 95\% CI, 1.42-7.70; $P=0.005$ ).

\section{DISCUSSION}

The clinical presentation of CUP that showed early and usually aggressive metastatic dissemination with limited life expectancy require the identification of favorable patient groups. In the present study, a consecutive series of cases of CUPs in one institute was analyzed to identify the clinicopathologic factors related to patient survival. Limited information was provided by previous literature regarding the natural course of the disease and the biologic mechanism that explain the clinical manifestation of CUP. In the early nineties, a large series with 657 consecutive patients, reported decreased survival in cases with men, more organ site, adenocarcinoma histology, metastasis to lung, bone and pleura [14]. Since then, the importance of biomarkers and their identification by IHC has been extensively researched. We validated previously reported clinicopathologic factors associated with worse prognosis such as adenocarcinoma histology, multiple metastases beyond lymph nodes, bone metastases and good risk group based on Culine's prognostic model in this cohort. Several clinicopathologic factors related with adverse clinical outcome of CUPs were suggested including adenocarcinoma histology, poor performance status, multiple disseminated metastases, and elevated LDH, compatible with the results of this study, and they are summarized in Table 4.
Unique findings in this cohort were the relation between expressions of biomarkers with the unfavorable clinical behaviors. CA19-9, CEA, and LDH elevation in the serum test and CK20 positivity in the tumor tissue were proven to be related with the shorter overall survival in univariate analysis. Especially, CK20 positivity was related to unfavorable overall survival in the multivariable analysis. Prognostic value of CK20 expression was validated in a subset of urothelial carcinomas and colorectal carcinomas [15-17]. This type of keratin, CK20, is a major cellular protein of mature enterocytes and goblet cells and specially expressed in the gastric and intestinal mucosa, suggesting that CUP with immunophenotype of enterocytes may have intrinsic aggressive biological behavior.

The potential limitation of this study is that the patient survival was not separately analyzed in the context of therapy given to each patient. Ever since new, broad spectrum antineoplastic chemotherapeutic drugs were introduced around late 1990s, combination of taxane and a platinum agent or gemcitabine and a platinum agent have been most commonly used for the treatment of the CUPs, but growing evidence showed a site-specific therapy based on the identified primary tumor type result in improved patient survival $[3,18]$. In this regard, recent research showing epigenetic profile guided tumor type specific therapy showing improved overall survival compared with that in patients who received empiric therapy is astonishing [10]. Tests based on mRNA or miRNA profile are commercially available and they appear to show reproducible results. Although the practical use of these approaches need to be studied in the light of cost and feasibility in the clinical practice, identification of subgroups that may be eligible for site specific therapy seems to be the most important question for the improvement of survival of patient with CUP. 
Prognostic model suggested by Culine was also validated in this cohort, suggesting that it would be appropriate to include this model in early clinical evaluation, considering its conciseness. Recently, Culine's model was validated in 47 cancer of unknown primary origin in adolescents (CUP-AYA) [19]. Nevertheless, the clinical utility of this model need to be regarded in the context of the treatment as the current NCCN guideline suggests the site-specific treatment of CUP based on the information from the work-up as best as can be done.
In conclusion, clinicopathologic factors related to the patient survival was analyzed, revealing CK20 expression, adenocarcinoma histology, multiple metastases beyond lymph nodes, bone metastases, poor risk groups based on Culine's models are factors related unfavorable outcome. Significance of these factors need to be considered in the context of eligibility of patients for the site-specific therapies.
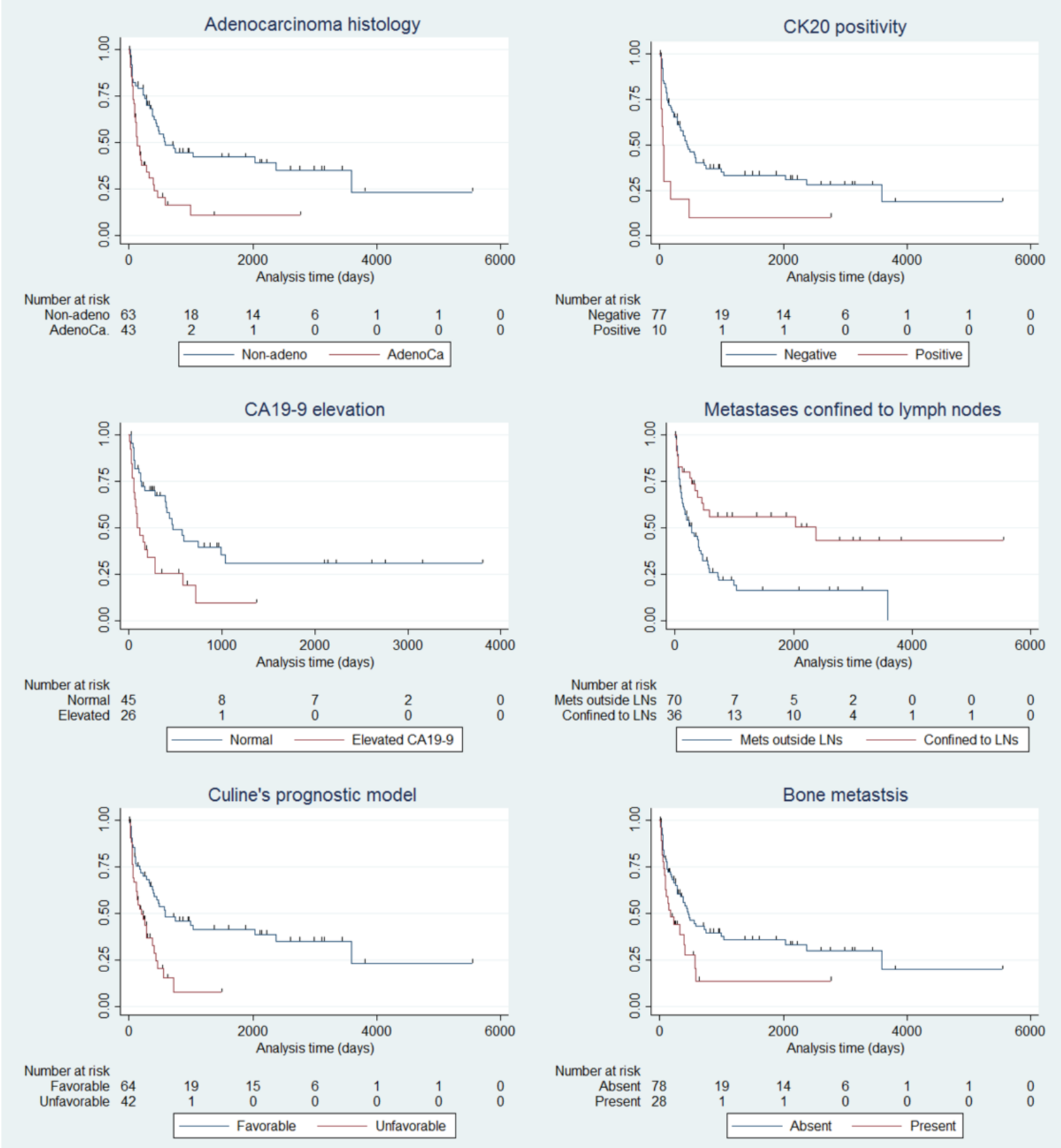

Figure 3: Kaplan-Meier survival estimates of CUP patients according to the clinicopathologic factors. Adenocarcinoma histology $(P=0.001)$, increased CA19-9 $(P=0.003)$, patients belonging to poor risk group in Culine's model $(P<0.001)$, CK20 positivity $(P=0.002)$, metastasis not confined to the lymph nodes $(P=0.0015)$, and presence of bone metastasis $(P=0.017)$ were factors related with unfavorable clinical outcome. 
Table 4: Previous studies of prognostic factors in patients with CUP

\begin{tabular}{|c|c|c|c|}
\hline \multirow{2}{*}{ Reference } & \multirow{2}{*}{ Number of Patients } & \multicolumn{2}{|l|}{ Adverse prognostic factors } \\
\hline & & Univariated analysis & Multivariable analysis \\
\hline \multirow[t]{2}{*}{ Kambhu [21] } & 57 & Poor performance status & Visceral metastases below the diaphragm \\
\hline & & Visceral metastases below the diaphragm & \\
\hline \multirow[t]{5}{*}{$\begin{array}{l}\text { Hainsworth } \\
{[14]}\end{array}$} & 220 & $\begin{array}{l}\text { Dominant tumor location } \\
\text { retroperitoneum and peripheral lymph } \\
\text { nodes }\end{array}$ & $\begin{array}{l}\text { Dominant tumor location outside } \\
\text { retroperitoneum and peripheral lymph } \\
\text { nodes }\end{array}$ \\
\hline & & Number of metastatic sites $(>3)$ & Number of metastatic sites $(>3)$ \\
\hline & & Elevated serum CEA & Positive smoking history \\
\hline & & Elevated serum LDH & Older age \\
\hline & & Positive smoking history & \\
\hline \multirow[t]{8}{*}{$\begin{array}{l}\text { Abbruzzese } \\
{[22]}\end{array}$} & 657 & Male & Male \\
\hline & & Adenocarcinoma histology & Adenocarcinoma histology \\
\hline & & Number of metastatic sites & Number of metastatic sites \\
\hline & & Lung metastases & Liver metastases \\
\hline & & Liver metastases & \\
\hline & & Bone mtastases & \\
\hline & & Pleura metastases & \\
\hline & & Brain metastases & \\
\hline \multirow[t]{6}{*}{$\begin{array}{l}\text { van der Gaast } \\
{[23]}\end{array}$} & 79 & Poor performance status & Poor performance status \\
\hline & & Adenocarcinoma histology & Elevated serum alkaline phosphatase \\
\hline & & Bone mtastases & \\
\hline & & Liver metastases & \\
\hline & & Elevated serum alkaline phosphatase & \\
\hline & & Serum AST & \\
\hline \multirow[t]{4}{*}{ Culine [13] } & 150 & Performance status 2 or 3 & Performance status 2 or 3 \\
\hline & & Liver metastases & Elevated serum LDH \\
\hline & & Elevated serum alkaline phosephatase & \\
\hline & & Elevated serum LDH & \\
\hline \multirow[t]{5}{*}{ Raghav [19] } & 47 & Number of metastatic sites $>3$ & Number of metastatic sites $>3$ \\
\hline & & Elevated LDH & Elevated LDH \\
\hline & & Lung metastases & Tissue of origin not tested \\
\hline & & First line treatment & \\
\hline & & Tissue of origin not tested & \\
\hline
\end{tabular}

\section{MATERIALS AND METHODS}

\section{Patient selection}

This retrospective study was approved by the Institutional Review Board of Yonsei University Medical Center (approval number: 4-2015-0830). A total of 106 consecutive cases from 106 patients of carcinoma of unknown primary origin were collected from the archives of pathology in Severance hospital during the period of 2000 to 2015. Patient records/information were anonymized and de-identified prior to clinicopathologic analyses. Vital status of the patient was confirmed by the national tumor registry and electronic medical record of the patients.

The diagnostic inclusion criteria were adopted from the research of previously reported literatures $[1,20]$.

Clinically metastatic disseminated tumor

No definite increased specific serum tumor marker that can explain the lesion.

No identified primary tumor site at presentation

Limited to epithelial and undifferentiated cancers

\section{Stratification of the patients}

To categorize the cases into 'favorable' and 'nonfavorable' groups, the following criteria were adopted from literatures [6].

Women with papillary adenocarcinoma of the peritoneal cavity 
Women with adenocarcinoma involving the axillary lymph nodes

Poorly differentiated carcinoma with midline distribution

Poorly differentiated neuroendocrine carcinoma nodes

Squamous-cell carcinoma involving cervical lymph

Adenocarcinoma with a colon-cancer profile (CK20+, CK7-, CDX2+)

Men with blastic bone metastases and elevated prostate-specific antigen (adenocarcinoma)

Isolated inguinal adenopathy (squamous carcinoma)

Patients with one small, potentially resectable tumour

In addition, Culine's prognostic model was applied and we classified the patients into group with good risk (ECOG performance status of 0 or 1 and normal LDH or no evidence of liver metastases if $\mathrm{LDH}$ is unknown) and poor risk (ECOG performance status of 2 or more or elevated $\mathrm{LDH}$ or presence of liver metastases if $\mathrm{LDH}$ unknown) [13].

\section{Generation of tissue microarray}

A representative area of $\mathrm{H} \& \mathrm{E}$ stained slides of each tumor and the corresponding spot was marked on the paraffin block. The area was punched out by the biopsy needle and a 3-mm tissue core was placed into a recipient block. More than 2 tissue cores were extracted to minimize extraction bias. Each tissue core was assigned.

\section{Immunohistochemistry}

We used a two-step strategy of IHC to assess CUPs according NCCN Guidelines [1]. First, we identified that tumors with occult primary tissue of origin were carcinomatous tumors using the following antibodies: broad spectrum cytokeratin (CK), S-100 protein, HMB45, and CD45. Next, staining for CK7 and CK20 is used to subtype carcinomas. We also used CDX-2 antibody because a recent report presented that patients with CUPs with lower gastrointestinal profile (CDX-2+, CK20+, CK7-) may have benefit from site-specific therapy [18]. Neuroendocrine differentiation was identified using IHCs for synaptophysin, chromogranin and CD56 in cases with histology with organoid arrangement such as solid/nesting, trabecular or gyriform pattern. Information of primary antibodies is presented as Supplementary Table 1.

Formalin-fixed, paraffin-embedded tissue sections from the tissue microarray were prepared for IHC. Briefly, $5-\mu \mathrm{m}$-thick sections were obtained with a microtome, transferred into adhesive slides, and dried at $62^{\circ} \mathrm{C}$ for 30 minutes. IHC was performed using an automated staining instrument (Ventana Discovery ${ }^{\circledR}$ XT, Ventana Medical System, AZ, USA) according to instruction.

\section{Statistics}

Patients and tumor characteristics including age, gender, histologic type, treatment, immunohistochemistry against CK7, CK20 and CDX2, tumor markers (CEA, CA19-9, CA 12-5, CA 15-3, SCCAg, AFP, PIVKA-II), site of metastases were summarized using frequencies and percentages. Analysis of overall survival was performed using Kaplan-Meier's method and log-rank tests. For adjustment of parameters affecting a patient's survival, multivariable analysis was performed using Cox regression test. We checked the proportionality assumption of each variable using stphplot function of STATA software. Statistical significance was reached when $P<$ 0.05 . Data were analyzed using TitleIBM Corp. Released 2013. IBM SPSS Statistics for Windows, Version 22.0. Armonk, NY: IBM Corp.23 and Stata Statistical Software: Release 14. College Station, TX: StataCorp LP.

\section{ACKNOWLEDGMENTS}

This study was supported by a faculty research grant of Yonsei University College of Medicine [6-2015-0087 and 6-2016-0034 to SKK.]; the Basic Science Research Program through the National Research Foundation of Korea (NRF) funded by the Ministry of Education, Science and Technology [NRF 2014R1A1A1002443 to JC.].

\section{CONFLICTS OF INTERESTS}

The authors declare that they have no conflicts of interest in the article.

\section{REFERENCES}

1. Network NCC. Occult primary (cancer of unknown primary [CUP]) (version 2.2016). NCCN clinical practice guidelines in oncology.

2. Conner JR, Hornick JL. Metastatic carcinoma of unknown primary: diagnostic approach using immunohistochemistry. Adv Anat Pathol. 2015; 22:149-167.

3. Hainsworth JD, Rubin MS, Spigel DR, Boccia RV, Raby S, Quinn R, Greco FA. Molecular gene expression profiling to predict the tissue of origin and direct site-specific therapy in patients with carcinoma of unknown primary site: a prospective trial of the Sarah Cannon research institute. J Clin Oncol. 2013; 31:217-223.

4. Hemminki K, Bevier M, Hemminki A, Sundquist J. Survival in cancer of unknown primary site: populationbased analysis by site and histology. Ann Oncol. 2012; 23:1854-1863.

5. Massard C, Loriot Y, Fizazi K. Carcinomas of an unknown primary origin-diagnosis and treatment. Nat Rev Clin 
Oncol. 2011; 8:701-710.

6. Pavlidis N, Pentheroudakis G. Cancer of unknown primary site. The Lancet. 2012; 379:1428-1435.

7. Greco FA, Spigel DR, Yardley DA, Erlander MG, Ma XJ, Hainsworth JD. Molecular profiling in unknown primary cancer: accuracy of tissue of origin prediction. Oncologist. 2010; 15:500-506.

8. Ferracin M, Pedriali M, Veronese A, Zagatti B, Gafa R, Magri E, Lunardi M, Munerato G, Querzoli G, Maestri I, Ulazzi L, Nenci I, Croce CM, et al. MicroRNA profiling for the identification of cancers with unknown primary tissueof-origin. J Pathol. 2011; 225:43-53.

9. Varadhachary GR, Spector Y, Abbruzzese JL, Rosenwald S, Wang H, Aharonov R, Carlson HR, Cohen D, Karanth S, Macinskas J, Lenzi R, Chajut A, Edmonston TB, et al. Prospective gene signature study using microRNA to identify the tissue of origin in patients with carcinoma of unknown primary. Clin Cancer Res. 2011; 17:4063-4070.

10. Moran S, Martinez-Cardus A, Sayols S, Musulen E, Balana C, Estival-Gonzalez A, Moutinho C, Heyn H, Diaz-Lagares A, de Moura MC, Stella GM, Comoglio PM, Ruiz-Miro $\mathrm{M}$, et al. Epigenetic profiling to classify cancer of unknown primary: a multicentre, retrospective analysis. Lancet Oncol. 2016; 17:1386-1395.

11. Bahrami A, Truong LD, Ro JY. Undifferentiated tumor: true identity by immunohistochemistry. Arch Pathol Lab Med. 2008; 132:326-348.

12. Chu PG, Weiss LM. Keratin expression in human tissues and neoplasms. Histopathology. 2002; 40:403-439.

13. Culine S, Kramar A, Saghatchian M, Bugat R, Lesimple T, Lortholary A, Merrouche Y, Laplanche A, Fizazi K, French Study Group on Carcinomas of Unknown P. Development and validation of a prognostic model to predict the length of survival in patients with carcinomas of an unknown primary site. J Clin Oncol. 2002; 20:4679-4683.

14. Hainsworth JD, Johnson DH, Greco FA. Cisplatinbased combination chemotherapy in the treatment of poorly differentiated carcinoma and poorly differentiated adenocarcinoma of unknown primary site: results of a 12year experience. J Clin Oncol. 1992; 10:912-922.

15. Otto W, Denzinger S, Fritsche HM, Burger M, Rossler W, Bertz S, May M, Hartmann A, Hofstadter F, Wieland WF, Eder F. Introduction and first clinical application of a simplified immunohistochemical validation system confirms prognostic impact of KI-67 and CK20 for stage $\mathrm{T} 1$ urothelial bladder carcinoma: single-center analysis of eight biomarkers in a series of three hundred six patients. Clin Genitourin Cancer. 2013; 11:537-544.
16. Imai Y, Yamagishi H, Fukuda K, Okamura T, Ono Y, Ban $\mathrm{S}$, Inoue $\mathrm{T}$, Ueda $\mathrm{Y}$. Expression of cytokeratin 20 indicates invasive histological phenotype in poorly differentiated colorectal adenocarcinoma. Anticancer Res. 2014; 34:159167.

17. Rosenberg R, Hoos A, Mueller J, Baier P, Stricker D, Werner M, Nekarda H, Siewert JR. Prognostic significance of cytokeratin-20 reverse transcriptase polymerase chain reaction in lymph nodes of node-negative colorectal cancer patients. J Clin Oncol. 2002; 20:1049-1055.

18. Varadhachary GR, Karanth S, Qiao W, Carlson HR, Raber $\mathrm{MN}$, Hainsworth JD, Greco FA. Carcinoma of unknown primary with gastrointestinal profile: immunohistochemistry and survival data for this favorable subset. Int J Clin Oncol. 2014; 19:479-484.

19. Raghav K, Mhadgut H, McQuade JL, Lei X, Ross A, Matamoros A, Wang H, Overman MJ, Varadhachary GR. Cancer of Unknown Primary in Adolescents and Young Adults: Clinicopathological Features, Prognostic Factors and Survival Outcomes. PLoS One. 2016; 11:e0154985.

20. Bugat R, Bataillard A, Lesimple T, Voigt JJ, Culine S, Lortholary A, Merrouche Y, Ganem G, Kaminsky MC, Negrier S, Perol M, Laforet C, Bedossa P, et al. Summary of the Standards, Options and Recommendations for the management of patients with carcinoma of unknown primary site (2002). Br J Cancer. 2003; 89:S59-66.

21. Kambhu SA, Kelsen DP, Fiore J, Niedzwiecki D, Chapman D, Vinciguerra V, Rosenbluth R. Metastatic adenocarcinomas of unknown primary site. Prognostic variables and treatment results. Am J Clin Oncol. 1990; 13:55-60.

22. Abbruzzese JL, Abbruzzese MC, Hess KR, Raber MN, Lenzi R, Frost P. Unknown primary carcinoma: natural history and prognostic factors in 657 consecutive patients. J Clin Oncol. 1994; 12:1272-1280.

23. van der Gaast A, Verweij J, Planting AS, Hop WC, Stoter G. Simple prognostic model to predict survival in patients with undifferentiated carcinoma of unknown primary site. $\mathrm{J}$ Clin Oncol. 1995; 13:1720-1725. 